\title{
SISTEMATIZAÇÃO DE PRINCÍPIOS E REGRAS CONSTITUCIONAIS TENDO EM VISTA O PRINCÍPIO DA PUBLICIDADE E A PROPAGANDA DOS ÓRGÃOS PÚBLICOS
}

\author{
CONSTITUTIONAL PRINCIPLES AND RULE'S \\ SYSTEMATIZATION CONSIDERING THE ADVERTISING \\ PRINCIPLE OF THE PUBLIC AGENCIES
}

\author{
Marcos Antônio Striquer Soares"
}

\begin{abstract}
Resumo: Analisa a inserção de princípios e regras constitucionais em um sistema jurídico constitucional para compreender as possibilidades de utilização e aplicação do princípio da publicidade e da propaganda dos órgãos públicos. Verifica os limites de interpretação da Constituição, para permitir a demarcação de situações-limite, em que a autoridade administrativa deva praticar atos ou omitir-se quando estiver em questão a publicidade dos órgãos públicos e a realização de propaganda do governo. Conclui que o uso indiscriminado da propaganda pelos órgãos públicos exige cuidado especial do aplicador da Constituição, quando de sua interpretação, para coibir seu uso em proveito de interesses estranhos ao interesse público.
\end{abstract}

Palavras-chave: Princípios Constitucionais, Princípio da Publicidade, Propaganda dos Órgãos Públicos, Sistema Jurídico, Interpretação Constitucional.

\begin{abstract}
This paper analyzes the insertion of constitutional principles and rules in a constitutional juridical system in order to understand the possibilities of use and application of the publicity principle and the advertising of public institutions. It verifies the limits of interpretation of the Constitution, in order to enable the demarcation of limit-situations, in which the administrative authority should make decisions or omit itself when the issue of publicity of public institutions and the government advertising are in question. It concludes that the wholesale use of advertising on the part of public institutions demands a special attention of the person who applies the Constitution, while interpreting it, in order to stop its use in the benefit of unusual interests to the public concern.
\end{abstract}

Key words: Constitutional Principles, Publicity Principle, Advertising of Public Institutions, Juridical System, Constitutional Interpretation.

\footnotetext{
"Mestre e doutor em Direito do Estado/Direito Constitucional pela Pontifícia Universidade Católica de São Paulo; professor de Direito Constitucional na Universidade Estadual de Londrina na graduação em Direito e no mestrado em Direito Negocial; professor de Direito Constitucional na UniFil.
} 


\section{INTRODUÇÃO}

As leis dos nossos tempos já não podem ser compreendidas pela análise simplista de seus termos. A Constituição, especialmente, apresenta um volume enorme de informações cuja análise e compreensão demanda cuidado e atenção especial do estudioso do Direito. As Constituições, hoje, são leis do tempo em que são aplicadas, e não do tempo em que foram criadas. Além disso, uma sociedade, na qual a democracia ainda depende do estabelecimento de instituições confiáveis, necessita de critérios que viabilizem decisões judiciais imparciais, mas também decisões judiciais que se aproximem, na melhor medida possível, da idéia de justiça para determinado caso concreto.

Conhecer e compreender nossa Constituição pressupõe o estudo de temas que não estão positivados. São temas que devem ser situados como referências iniciais para o estudo dessa Lei. Dentre estes temas, três se destacam por carecerem de entrelaçamento e harmonia: princípios constitucionais, sistema jurídico constitucional e interpretação da constituição.

O princípio, enquanto norma jurídica, é dotado de alto grau de generalidade e abstração; sua aplicação isolada torna-o sem sentido, pois, dotado de alto grau de generalidade e abstração, com muitos significados, ele queda sem significado algum, ficando na dependência da conjugação com outros elementos para determinação de seu conteúdo no instante histórico de sua aplicação, em dada sociedade. Daí a necessidade de alocá-lo em um sistema jurídico, para delimitar sua abrangência; daí, também, a necessidade de estudos específicos de interpretação da Constituição. Esses princípios, com as regras constitucionais, delimitam as possibilidades de exercício do poder do Estado, além disso, são marcos iniciais do ordenamento jurídico, pontos de partida do comportamento social; interpretá-los exige cuidados especiais do intérprete.

Para facilitar a compreensão desses três temas, o presente estudo passa à análise da publicidade dos comportamentos da Administração Pública, examinando, então, o significado dos diversos dispositivos constitucionais referentes a esse assunto. Segue, portanto, o estudo destes três temas. 


\section{OS PRINCÍPIOS CONSTITUCIONAIS}

A Constituição é, basicamente, uma norma que reúne princípios. Também contém regras, mas disciplina o campo social que pretende atingir principalmente por princípios. Mesmo uma Constituição prolixa e detalhista, como a brasileira, tem uma estrutura é principiológica. Os princípios constitucionais apresentam-se, assim, como os fundamentos do Estado mas não podemos esquecer que, isoladamente, possuem múltiplos significados e, bem por isto, isoladamente ficam destituídos de conteúdo jurídico.

Preliminarmente, é necessário examinar a natureza dos princípios constitucionais, as características que os demarcam e as funções que exercem no ordenamento jurídico para, ao final, a partir dos dados reunidos, estabelecer um conceito.

A) Natureza dos princípios.- Quanto à natureza, a doutrina tem afirmado que os princípios possuem natureza jurídica. Conforme Canotilho (1993, p. 183), princípios constitucionais valem como "lei"; o Direito Constitucional é direito positivo. Conforme Cármen Lúcia Antunes Rocha, "os princípios constitucionais têm normatividade incontestável, quer dizer, contêm-se nas normas jurídicas do sistema fundamental” $(1998,26)$.

A eficácia jurídica dos princípios constitucionais foi sendo construída a partir da idéia de ser a Constituição uma lei e, como tal, carregada da coercitividade que domina todas as formas legais. Daí que os princípios fundamentais foram crescendo em importância e eficiência nos últimos séculos, até adquirir foros de ordem definida e definidora de todas as regulações jurídicas (ROCHA, 1994, p. 42).

Os princípios têm, desse modo, sede na lei. Em nosso caso, são encontrados na Constituição. Por vezes constam expressamente dela, por vezes estão implícitos. "Todos os princípios jurídicos, inclusive os implícitos, têm sede direta no ordenamento jurídico. Não cabe ao jurista inventar os 'seus princípios'. Os princípios implícitos são tão importantes quanto os explícitos; constituem, com estes, verdadeiras normas jurídicas" (SUNDFELD, 1993, p. 143-144). "Não importa se o princípio é implícito ou explícito, mas, sim, se existe ou não existe” (CARRAZZA, 1991, p. 26). Cabe ao estudioso do Direito encontrá-los e determinar o seu significado.

B) Características dos princípios.- Enquanto espécies de normas jurídicas, os princípios apresentam características próprias que os diferenciam das demais espécies de normas, as regras jurídicas. São elementos específicos de todo e qualquer princípio, que os particulariza e distingue em relação às regras. 
Examinando os textos sobre princípios constitucionais, constatamos uma diversidade de características apresentadas pelos diversos autores (CANOTILHO, 1993; ROCHA, 1994)1.

Para atingir o objetivo pretendido neste trabalho, não é necessário estudar cada uma delas, rebuscando infinitos dados diferenciadores e comuns, mesmo porque não há uma orientação uniforme na doutrina. Para firmar, ao final, nossas conclusões, fixamos como base de sustentação três características dos princípios constitucionais.

A característica mais citada pela doutrina é o elevado grau de generalidade e abstração. O princípio é geral porque comporta uma

${ }^{1}$ Canotilho apresenta as seguintes características dos princípios, diferenciando-os das regras jurídicas: “a) Grau de abstracção: os princípios são normas com um grau de abstracção relativamente elevado; de modo diverso, as regras possuem uma abstracção relativamente reduzida. b) Grau de determinabilidade na aplicação do caso concreto: os princípios, por serem vagos e indeterminados, carecem de mediações concretizadoras (do legislador? Do juiz?), enquanto as regras são susceptíveis de aplicação direta. c) Carácter de fundamentalidade no sistema das fontes de direito: os princípios são normas de natureza ou com um papel fundamental no ordenamento jurídico devido à sua posição hierárquica no sistema das fontes (ex: princípios constitucionais) ou à sua importância estruturante dentro do sistema jurídico (ex: princípio do Estado de Direito). d) "Proximidade" da ideia de direito: os princípios são "standards" juridicamente vinculantes radicados nas exigências de "justiça" (Dwordin) ou na "ideia de direito" (Larenz); as regras podem ser normas vinculativas com um conteúdo meramente funcional. e) Natureza normogenética: os princípios são fundamento de regras, isto é, são normas que estão na base ou constituem a ratio de regras jurídicas, desempenhando, por isso, uma função normogenética fundamentante." Carmen Lúcia Antunes Rocha também apresenta um conjunto de características dos princípios constitucionais, "que denotam a sua natureza singular e especificam as funções que se prestam a realizar no Direito", são eles: Generalidade: significa que eles não pontuam com especificidade e minudência hipóteses concretas de regulações jurídicas; Primariedade: dos princípios constitucionais decorrem outros princípios, que são subprincípios em relação aos anteriores; Dimensão axiológica: têm dimensão axiológica por causa do conteúdo ético de que se dotam; Objetividade: conquanto caracterizados pela generalidade de seus conteúdos, eles são dotados de objetividade. Não se cuida, pois, de conteúdos subjetivos ou aleatórios. Têm substância jurídica própria, cuja explicitação é tarefa do aplicador das normas nas quais eles se contêm; Transcendência e atualidade: a transcendência está em que superam a elaboração normativa constitucional formal e medram no ordenamento estatal como a mais vigorosa diretriz política, legislativa, administrativa e jurisdicional. A atualidade e atualização impõe-se porque, sem esta perfeita sincronia entre as bases modelares de um ordenamento jurídico-estatal e o ideário político e jurídico vivenciado em determinado momento pelo povo de um Estado, não há como assegurar a eficácia e a efetividade do sistema normativo e sem isto não há como garantir a estabilidade e a persistência do próprio Estado; Polimorfia: os princípios constitucionais têm 
série indefinida de aplicações (GRAU, 1997)2. É esclarecedora uma passagem de Celso Ribeiro Bastos, quando trata dos princípios como valor, segundo ele, à medida que os princípios

[...] perdem o seu caráter de precisão de conteúdo, isto é, conforme vão perdendo densidade semântica, eles ascendem a uma posição que lhes permite sobressair, pairando sobre uma área muito mais ampla do que uma norma estabelecedora de preceitos. Portanto, o que o princípio perde em carga normativa ganha como força valorativa a espraiar-se por cima de um sem-número de outras normas (BASTOS, 1997, p. 153-154).

Outra característica importante é a sua capacidade de estender sua força normativa por todo o ordenamento jurídico, apresentando-se como base de sustentação de todo o sistema jurídico - daí, também, a importância de estudarmos o sistema jurídico, em seguida.

Violar um princípio é muito mais grave que transgredir uma norma qualquer. A desatenção ao princípio implica ofensa não apenas a um específico mandamento obrigatório, mas a todo o sistema de comandos. É a mais grave forma de ilegalidade ou inconstitucionalidade, conforme o escalão do princípio atingido, porque representa insurgência contra todo o sistema, subversão de seus valores fundamentais, contumélia irremissível a seu arcabouço lógico e corrosão de sua estrutura mestra (MELLO, 2001, p. 772).

Por fim, ainda cabe ressaltar como característica dos princípios jurídicos a dependência de mediação de lei ou de decisão judicial: "os princípios, por serem vagos e indeterminados, carecem de mediações concretizadoras" (CANOTILHO, 1993, p. 166). Sua aplicabilidade, os efeitos que podem produzir, depende, em grande parte, de decisão concretizadora (daí, também,

substância política ativa, que os torna passíveis de serem mutáveis para se adaptarem às novas contingências sociais apresentadas e sedimentadas; Vinculabilidade e aderência: a vinculabilidade exprime o vigor jurídico de que se revestem, a determinar que todas as regras do sistema constitucional, bem como todas as normas que compõem o ordenamento jurídico, se liguem ao quanto principiologicamente definido. A aderência é característica que enfatiza a sua vinculabilidade; Informatividade: são informativos de todo o sistema jurídico de um Estado; Complementariedade: os princípios constitucionais são condicionantes uns dos outros; Normatividade jurídica: são eles veiculados pelas normas jurídicas fundamentais. ${ }^{2} \mathrm{O}$ autor citado faz um exame comparativo entre a generalidade de princípios e regras: "[...] a generalidade da regra jurídica é diversa da generalidade de um princípio jurídico. Demonstrao Boulanger observando que a regra é geral porque estabelecida para um número indeterminado de atos ou fatos. Não obstante, ela é especial na medida em que não regula senão tais atos ou tais fatos: é editada para ser aplicada a uma situação jurídica determinada. Já o princípio, ao contrário, é geral porque comporta uma série indefinida de aplicações”. 
a importância de conjugar esse tema com o estudo sobre interpretação da Constituição), que viabiliza seus efeitos potenciais. É evidente que eles possuem eficácia jurídica independentemente dessas decisões intermediárias, mas com grau reduzido (SILVA, 1982) ${ }^{3}$, diante do potencial normativo que carregam.

C) As funções dos princípios.- $O$ terceiro ponto levantado entre os muitos textos sobre o assunto é a função dos princípios no ordenamento jurídico. Cabe aqui a análise do papel que eles desempenham no ordenamento jurídico ou, um pouco-além disso, a ação que eles provocam em meio às normas jurídicas, no sistema jurídico. Encontramos em Luís Roberto Barroso uma síntese desses papéis dos princípios. Ensina o autor, os princípios

[...] passaram a ser a síntese dos valores abrigados no ordenamento jurídico. Eles espelham a ideologia da sociedade, seus postulados básicos, seus fins. Os princípios dão unidade e harmonia ao sistema, integrando suas diferentes partes e atenuando tensões normativas. De parte isto, servem de guia para o intérprete, cuja atuação deve pautar-se pela identificação do princípio maior que rege o tema apreciado, descendo do mais genérico ao mais específico, até chegar à formulação da regra concreta que vai reger a espécie. Estes os papéis desempenhados pelos princípios: a) condensar valores; b) dar unidade ao sistema; c) condicionar a atividade do intérprete (2001, p. 105-106).

Tais funções dos princípios devem ter tratamento meticuloso, pelo operador do direito, pois a característica de norma, assumida por eles, pressupõe bom desempenho dessas funções, desses papéis dos princípios no mundo jurídico, na manifestação dos operadores. Isso decorre da consideração dos princípios como norma dotada de alto grau de abstração. Nesse ambiente difuso, a convivência de valores e a ação, muitas vezes personalista do intérprete, podem provocar verdadeiros arbítrios para a sociedade.

\footnotetext{
3 Diz José Afonso da Silva: "A eficácia jurídica da norma designa a qualidade de produzir, em maior ou menor grau, efeitos jurídicos, ao regular, desde logo, as situações, relações e comportamentos nela indicados; nesse sentido, a eficácia diz respeito à aplicabilidade, exigibilidade ou executoriedade da norma, como possibilidade de sua aplicação jurídica. Possibilidade e não efetividade.”
} 
A primeira função do princípio, então, é a sua capacidade de condensar valores. Não há dúvida de que há uma carga axiológica inserida na Lei Maior de cada Estado. Conforme Celso Ribeiro Bastos (1999), as Constituições são tributárias de um conjunto de opções axiológicas. Não há Constituição neutra. Diante dos plúrimos valores que encerra, a sociedade humana tem de encampar um ou mais deles. Ivo Dantas (1995) fala em Ideologia Constitucional, significando opção em face de vários modelos políticos, econômicos e sociais disponíveis para reger os destinos da sociedade. Neste sentido ideologia é um conjunto de juízos de valor sobre matérias políticas, econômicas, sociais, culturais etc., que, em conseqüência de sua aceitação pela maioria dos diversos segmentos sociais, transformar-se-á em valores da própria sociedade.

O reconhecimento de valores inseridos na norma jurídica (o que vem se tornando quase unanimidade entre os estudiosos do Direito) marca um dos instantes de superação do positivismo jurídico (BOBBIO, 1995) ${ }^{4}$. Isto ocorre, porém, sem o retorno a um jusnaturalismo mítico de uma lei divina ou de uma ética sobre-humana. A inserção de conteúdo axiológico na norma jurídica deve ter como referência não uma lei divina ou uma ética sobre-humana, mas a própria condição humana, com sua exigência, entre outras, de convivência social.

Miguel Reale (1981) expressa esse conteúdo da norma jurídica extraindoo do ambiente de vida do homem: o Direito é uma realidade históricocultural ao qual correspondem três aspectos básicos, segundo o autor da teoria tridimensional, entre os quais, um aspecto axiológico (o Direito como valor de Justiça). Na linha culturalista de Miguel Reale (1981), o Direito é fruto do "construído" pelo homem, daquilo que ele acrescenta à natureza, é fruto da "cultura", sendo esta considerada como o conjunto de tudo aquilo que, nos planos material e espiritual, o homem constrói sobre a base da natureza, quer para modificá-la, quer para modificar-se a si mesmo. É, desse modo, o conjunto dos utensílios e instrumentos, das obras e serviços, assim como das atitudes espirituais e formais de comportamento que o homem veio formando e aperfeiçoando, através da história, como cabedal ou

\footnotetext{
${ }^{4}$ Bobbio, discorrendo sobre juízo de validade e juízo de valor, explica que o positivismo jurídico assume uma postura científica avalorativa diante do direito e "essa atitude contrapõe o positivismo jurídico ao jusnaturalismo, que sustenta que deve fazer parte do estudo do direito real também a sua valoração com base no direito ideal, pelo que na definição do direito se deve introduzir uma qualificação, que discrimine o direito tal qual é segundo um critério estabelecido do ponto de vista do direito tal qual deve ser.”
} 
patrimônio da espécie humana. Daí decorrem os valores: não vivemos no mundo de maneira indiferente, sem rumos ou sem fins, continua o mestre, a vida humana é sempre uma procura de valores. Viver é indiscutivelmente optar diariamente, permanentemente, entre dois ou mais valores. A existência é uma constante tomada de posição segundo valores. Se suprimirmos a idéia de valor, perderemos a substância da própria existência humana. Viver é, por conseguinte, uma realização de fins.

Desse modo, analisados os princípios, devemos passar ao estudo do sistema jurídico e da interpretação da Constituição. Mas já está evidente que o princípio deve ser vetor para o intérprete. Isso ocorre com o respeito às opções políticas inseridas nos princípios constitucionais, as quais servem de parâmetros para a atividade dos operadores do direito. Contudo, considerando o alto grau de abstração dos princípios jurídicos e a existência de inúmeros deles, é indispensável a consolidação de um sistema jurídico, para que a interpretação não seja dispersiva. Antes, porém, da análise do sistema jurídico constitucional e da interpretação constitucional é preciso completar o estudo sobre norma jurídica, traçando o perfil das regras jurídicas, as quais também compõem o sistema jurídico e serão objeto de trabalho do intérprete.

Depois de toda a análise desenvolvida, podemos afirmar que princípio constitucional (MELLO, 2001) $)^{5}$ é a norma jurídica caracterizada como base do sistema jurídico e dotada de um alto grau de abstração, que contém pouca densidade semântica e maior conteúdo axiológico, é dependente da ação do intérprete para sua aplicação e tem como função expressar valores do povo e do Estado (REALE,

\footnotetext{
${ }^{5} \mathrm{Um}$ dos conceitos de princípio mais citado, entre os encontrados na doutrina pátria, é o de Celso Antônio Bandeira de Mello, o qual não poderíamos deixar de transcrever: princípio "é, por definição, mandamento nuclear de um sistema, verdadeiro alicerce dele, disposição fundamental que se irradia sobre diferentes normas compondo-lhes o espírito e servindo de critério para sua exata compreensão e inteligência exatamente por definir a lógica e a racionalidade do sistema normativo, no que lhe confere a tônica e lhe dá sentido harmônico”.
} 
1960) ${ }^{6}$, dar unidade e harmonia ao sistema jurídico e orientar a interpretação da Constituição.

\section{AS REGRAS CONSTITUCIONAIS}

Vista a análise de princípio como espécie de norma, é preciso voltar às regras jurídicas. Elas também são espécies de normas jurídicas. São disposições destinadas a disciplinar a vida social, "carregadas da coercitividade que domina todas as formas legais”, dotadas, portanto, de força normativa para impor comportamentos ao homem.

Buscando suas características, encontramos em Canotilho:

possuem uma abstração relativamente reduzida; são suscetíveis de aplicação direta; podem ser normas vinculativas com um conteúdo meramente funcional. Assim, as regras possuem maior densidade semântica e podem ser aplicadas diretamente, sem necessidade de qualquer intermediação entre ela e o fato disciplinado (1993, p. 166-167).

Quanto à existência de conteúdo axiológico nas regras jurídicas, André Ramos Tavares explica:

[...] os valores superiores de determinado ordenamento jurídico estão vertidos tanto na forma principiológica (e aqui se têm os princípios constitucionais fundamentais) como na forma de regramento (trata-se de algumas regras jurídicas incorporadas à Constituição e que lhe conferem tonalidade própria juntamente com aqueles princípios fundamentais, sendo por isso igualmente consideradas fundamentais) (2002, p. 99).

Para Miguel Reale, "ao contrário das leis físico-matemáticas, as 'leis culturais' caracterizam-se por sua 'referibilidade a valores', ou, mais especificamente, por adequarem 'meios a fins"' (1981, p. 28). Nas regras jurídicas, portanto, também podemos encontrar conteúdo axiológico, mas isto não impede que elas incidam diretamente sobre a realidade. "Toda a norma é 'significativa', mas o significado não constitui um dado prévio; é,

${ }^{6}$ Explicando a titularidade da soberania, Miguel Reale escreve: "A soberania é substancialmente da Nação e só juridicamente é do Estado, o que quer dizer que, socialmente (mais quanto à fonte do poder), a soberania é da Nação, mas juridicamente (mais quanto ao exercício do poder) a soberania é do Estado." 
sim, o resultado da tarefa interpretativa" (CANOTILHO, 1993, p. $36)^{7}$. Cabe ao intérprete, ao aplicador da lei, expressar o significado desta.

Assim, em síntese, as regras constitucionais são normas jurídicas de maior densidade semântica e de aplicação direta, sem necessidade de qualquer intermediação entre ela e o fato disciplinado, sendo dotadas de conteúdo axiológico, a ser determinado pelo intérprete.

\section{O SISTEMA JURÍDICO CONSTITUCIONAL}

Conforme já referido, a compreensão dos princípios constitucionais como normas jurídicas pressupõe o conhecimento do sistema jurídico no qual esses princípios estão inseridos. Considerando que escolhemos a publicidade dos comportamentos da Administração Pública como tema de nosso estudo, devemos traçar, a seguir, as linhas necessárias para a compreensão da publicidade como princípio ou como regra jurídica. Assim, passemos ao estudo do tema sistema jurídico para entendermos, em seguida, o nosso objeto de estudo.

O sistema jurídico corresponde à organização das normas jurídicas, dispostas de modo a facilitar o conhecimento e o significado delas. A compreensão do Direito como sistema oferece, ao cientista, parâmetros para o desenvolvimento de sua pesquisa. Tercio Sampaio Ferraz Junior explica:

Sistema é sempre duas cousas: sistema é um conjunto de elementos e um conjunto de elementos que estão relacionados entre si. Assim, nesses termos, os elementos compõem aquilo que chamamos de repertório do sistema e as relações que estabelecemos entre os elementos compõem aquilo que chamamos de estrutura do sistema. [...] E, além disso, nós temos uma série de regras que unem esses elementos entre si (1973, p. 13) (grifo nosso).

\footnotetext{
7 Konrad Hesse, ao contrário, entende que nem toda a realização da norma constitucional é "interpretação". Este autor cita duas circunstâncias: não há interpretação, mas mera "atualização", quando o conteúdo das normas constitucionais é respeitado, sem que, possivelmente, exista consciência de que a Constituição está sendo aplicada, por exemplo, quando elegemos parlamentares; igualmente tampouco resulta necessário interpretar quando as disposições constitucionais são terminantes (tradução nossa).
} 
O sistema também é um conjunto limitado de elementos, "isto é, todo 'sistema' sugere, imediatamente, a idéia de que o sistema se limita. 'Sistema' é um conjunto, portanto, de elementos que pertencem ou de elementos que não pertencem a um sistema” (FERRAZ JUNIOR, 1973, p. 20).

A língua que falamos pode ser estudada como sistema. Ela possui um conjunto de elementos, as palavras; é o seu repertório. Ela possui regras de relacionamento dos elementos, as regras gramaticais, formando sua estrutura. É um exemplo de sistema. O Direito também pode ser estudado como sistema (BOBBIO, 1997) ${ }^{8}$.

O sistema não é uma realidade nem uma coisa objetiva; é o aparelho teórico mediante o qual se pode estudar a realidade. É, por outras palavras, o modo de ver, de ordenar, logicamente, a realidade, que, por sua vez, não é sistemática. Todo sistema é uma reunião de objetos e seus atributos (que constituem seu repertório) relacionados entre si, conforme certas regras. [...] o direito não é um sistema jurídico, mas uma realidade que pode ser estudada de modo sistemático pela Ciência do Direito. É indubitável que a tarefa mais importante do jurista consiste em apresentar o direito sob uma forma ordenada ou 'sistemática', para facilitar o seu conhecimento, bem como seu manejo por parte dos indivíduos que estão submetidos a ele, especialmente pelos que o aplicam (DINIZ, 1995, p. 26-27).

\section{Quando estudamos a Constituição como sistema (BONAVIDES, 2002)⿳⺈,}

\footnotetext{
${ }^{8}$ Norberto Bobbio anota: 'Entendemos por 'sistema' uma totalidade ordenada, um conjunto de entes entre os quais existe uma certa ordem. Para que se possa falar de uma ordem, é necessário que os entes que a constituem não estejam somente em relacionamento com o todo, mas também num relacionamento de coerência ente si. Quando nos perguntamos se um ordenamento jurídico constitui um sistema, nos perguntamos se as normas que o compõem estão num relacionamento de coerência entre si, e em que condições é possível essa relação".

${ }^{9}$ Paulo Bonavides traz passagem elucidativa quanto à dimensão do tema: "Todo o problema constitucional ainda hoje procede, contudo, da ausência de uma fórmula que venha combinar ou conciliar essas duas dimensões da Constituição: a jurídica e a política. A verdade é que ora prepondera uma, ora outra. No constitucionalismo clássico e individualista preponderou a primeira; no constitucionalismo social e contemporâneo, a segunda. E quando uma delas ocupa todo o espaço da reflexão e da análise, os danos e as insuficiências de compreensão do fenômeno constitucional se fazem patentes. O sistema constitucional surge pois como expressão elástica e flexível, que nos permite perceber o sentido tomado pela Constituição em face da ambiência social, que ela reflete, e a cujos influxos está sujeita, numa escala de dependência cada vez mais avultante. A terminologia sistema constitucional não é, assim, gratuita, pois induz a globalidade de forças e formas políticas a que uma Constituição necessariamente se acha presa”. Mais adiante, completa o referido autor: "Essa inserção da Constituição formal num sistema material e orgânico não só busca evitar o grave inconveniente de um normativismo extremo e abstrato, esvaziado de conteúdo material, a que de certo conduziria a posição Kelseniana - constitucionalismo jurídico impotente perante a Constituição real - como, por outra parte, serve ainda de valioso anteparo contra aqueles que, presos ao sociologismo de realidades inarredáveis e fatais, exprimem negação e ceticismo em face da eficácia normativa das Constituições. Nestas, a privação de juridicidade importa sempre subalternização e desprestígio, com graves danos para a proteção das liberdades humanas.”
} 
precisamos delimitar os seus elementos e determinar sua estrutura, suas regras de relacionamento, dando-lhe uma "espinha dorsal", uma referência de sustentação.

José Joaquim Gomes Canotilho (1993, p. 165) apresenta o sistema jurídico constitucional como "sistema normativo aberto de regras e princípios", constituído como "sistema aberto" porque as normas constitucionais têm disponibilidade e "capacidade de aprendizagem" para captarem a mudança da realidade e estarem abertas às concepções cambiantes da "verdade" e da "justiça" (FERRAZ JUNIOR, 1973) ${ }^{10}$.

Para Canotilho (1993, p. 180-183), a Constituição é formada por regras e princípios de diferente grau de concretização. Apresenta, em primeiro lugar, os princípios designados por "princípios estruturantes", constitutivos e indicativos das idéias directivas básicas de toda a ordem constitucional. São, por assim dizer, as traves-mestras jurídicoconstitucionais do estatuto jurídico do político. Estes princípios ganham concretização através de outros princípios (ou subprincípios) que "densificam" os princípios estruturantes, iluminando o seu sentido jurídico-constitucional e político-constitucional. Estes, denominados "princípios gerais fundamentais", podem, por sua vez, densificar-se ou concretizar-se ainda mais, através de outros princípios constitucionais, denominados "princípios constitucionais especiais". Os princípios estruturantes não são apenas densificados por princípios

\footnotetext{
${ }^{10}$ Sobre sistema aberto e sistema fechado, Tercio Sampaio Ferraz Junior apresenta as seguintes explicações: "Um sistema é fechado quando a introdução de um novo elemento o obriga a mudar o conjunto das regras, isto é, o obriga a fazer uma regra nova. [...] se eu puser um elemento novo dentro do jogo de xadrez, eu mudei a estrutura do jogo, eu fiz novas regras. O futebol também é um sistema fechado nesse sentido. Não posso ter um goleiro esquerdo, por exemplo. A introdução de novo elemento me obriga a uma mudança nas regras. Alguns sistemas são mais ou menos fechados, não são absolutamente rigorosos. Eu posso jogar futebol como numa pelada na praia. Posso jogar até com doze ou quinze, se for o caso.” Um sistema é aberto quando eu posso encaixar um elemento estranho, que vem de fora, que não pertence ao seu conjunto de elementos e, apesar disso, não preciso modificar sua estrutura, suas regras de relacionamento. "A língua é um sistema aberto. Admite um elemento novo sem modificar a estrutura”, ou seja, é possível incluir uma palavra estrangeira sem modificar as regras de relacionamento dos elementos do sistema. "Ocorre que isso tem um certo limite. Se, numa frase de cinco palavras, eu tiver quatro inglesas e uma portuguesa, eu quebro a estrutura do português. Então há um certo limite para a abertura de um sistema."
} 
constitucionais gerais ou especiais. A sua concretização é feita também por várias "regras constitucionais", qualquer que seja a sua natureza. Todos estes princípios e regras poderão ainda obter maior grau de concretização e densidade através da "concretização legislativa e jurisprudencial". Esta sistematização faz com que os princípios constitucionais, em graus diferentes, sejam completados uns pelos outros, do abstrato para o concreto, num preenchimento de espaços normativos deixados, densificando as normas constitucionais ${ }^{11}$.

Luís Roberto Barroso (1996, p. 145) também divide os princípios em três categorias $^{12}$, para efeito de sistematizá-los: os "princípios fundamentais" são os fundamentos da organização política do Estado; os "princípios constitucionais gerais" são, normalmente, importantes especificações dos princípios fundamentais e se aproximam daqueles que ele identificou em outra passagem como princípios definidores de direitos, eles não têm caráter organizatório do Estado, mas sim limitativo de seu poder, resguardando desde logo situações individuais - seu conteúdo tem menos de decisão política e mais de valoração ética; e os "princípios setoriais ou especiais", que são aqueles que presidem um específico conjunto de normas afetas a determinado tema, capítulo ou título da Constituição; eles se irradiam limitadamente, mas no seu âmbito de atuação são supremos.

Para melhor compreensão dos princípios estruturantes, vale a transcrição de ensinamentos de Pinto Ferreira. Este autor divide os princípios constitucionais em essenciais ou gerais (equiparados, aqui, aos princípios estruturantes de Canotilho) e derivados, conforme suas letras:

A ciência do direito constitucional induz da realidade histórico-social os lineamentos básicos, os grandes princípios constitucionais, que servem de base à estruturação do Estado. Os princípios essenciais assim estabelecidos são os summa genera do direito constitucional, fórmulas básicas ou postos-chaves de

${ }^{11}$ Podemos indicar, então, o seguinte esquema: princípios estruturantes " princípios constitucionais gerais « princípios constitucionais especiais « regras constitucionais « legislação e jurisprudência. Especificamente quanto aos princípios, tendo por base a Constituição portuguesa, Canotilho indica ( o que apresentamos aqui a título de exemplo) o princípio democrático, como estruturante; o princípio da soberania popular, como geral; e os princípios da liberdade de propaganda, igualdade de oportunidades e imparcialidade nas campanhas eleitorais como especiais. Eles se encontram em graus diferentes, uns em relação aos outros, densificando o especial ao geral, que densifica o estruturante .

${ }^{12}$ As três categorias de princípios citadas por Luís Roberto Barroso podem ser, tudo indica, equiparadas, respectivamente, às três categorias fixadas por Canotilho, já que aquele autor faz diversas referências a este. 
interpretação e construção teórica do constitucionalismo [...]. Eles podem ser reduzidos a um grupo de princípios gerais, nos quais se subsumem os princípios derivados, de importância secundária (1983, p. 16-18).

Mais adiante o autor enumera cinco grandes princípios do direito constitucional moderno: o princípio da supremacia da Constituição; o princípio democrático; o princípio liberal; o princípio do socialismo; e o princípio do federalismo.

4.1 Sistematização dos princípios e das regras da Constituição de 1988, tendo em vista a publicidade

Tendo por base a sistematização de Canotilho (1993), a qual tem por fundamento a Constituição portuguesa, e também os ensinamentos de Luís Roberto Barroso (2001), devemos localizar as diversas exigências de publicidade previstas na Constituição e alocá-las em um sistema jurídico, em um aparelho teórico que facilite o conhecimento de nosso objeto de estudo. Partindo, então, da existência de princípios e regras, devemos chegar à conjugação de tais normas, de modo a compreendermos a publicidade estatal no Brasil. Comecemos pelos princípios, pelos princípios estruturantes.

A) Princípios estruturantes.- Assim, quanto aos "princípios estruturantes", já tivemos oportunidade de analisá-los e concluímos pela existência dos seguintes, na Constituição de 1988: o princípio da supremacia da Constituição; o princípio democrático; o princípio federativo; o princípio republicano; o princípio da divisão funcional do poder. Qual, dentre eles, viabilizaria a publicidade (SOARES, 1997)?

Para alguns autores, a publicidade é princípio decorrente do princípio republicando; para outros, está relacionado ao Estado Democrático de Direito. Para Lucia Valle Figueiredo, “a república (res publica) demanda transparência” (2001, p. 60). Torquato Jardim (1991), examinando a organização do Estado brasileiro, afirma que a publicidade é característica do regime republicano. Por outro lado, Bernardo de Souza (1999), examinando a publicidade dos contratos da Administração Pública, considera a publicidade como inerente à ordem democrática. Para Carlos Ari Sundfeld, "a ampla publicidade 
no aparelho estatal é princípio básico e essencial ao Estado Democrático de Direito" (1993, p. 170-171). Odete Medauar (1998) apresenta a publicidade como reivindicação de democracia. Diz Celso Antônio Bandeira de Mello,

[...] não pode haver em um Estado Democrático de Direito, no qual o poder reside no povo (art. 1aㅗ parágrafo único, da Constituição), ocultamento aos administrados dos assuntos que a todos interessam, e muito menos em relação aos sujeitos individualmente afetados por alguma medida (2001, p. 84).

Cármen Lúcia Antunes Rocha (1994) apresenta o fundamento da publicidade tanto no princípio democrático como no republicano.

A idéia de República, no Estado moderno, nasceu em oposição à monarquia. "Tem prevalecido a classificação dualista de formas de governo em república e monarqui a, ou governo republicano e governo monárquico. Aquele caracterizado pela eletividade periódica do chefe de Estado, e este por sua hereditariedade e vitaliciedade" (SILVA, 2000). Além de tais características, encontradas na origem do instituto, a doutrina também tem indicado a exigência de responsabilidade dos governantes ante a irresponsabilidade dos monarcas (DALLARI, 1991).

Embora a diferenciação entre "monarquia e república" já não seja a essência da questão, ela ainda é importante para a compreensão do princípio republicano. As monarquias européias, referências dos teóricos, são constitucionais e democráticas, na atualidade. As idéias de hereditariedade, vitaliciedade e irresponsabilidade ficam bastante esvaziadas, pois os reis não exercem (ou exercem poucas) funções de governo. Hoje, merece destaque o papel ético e unificador que eles exercem dentro do Estado. Apesar disto a República ainda pode ser observada como exigência de responsabilidade, de compromisso com o povo e com o interesse público, basicamente, na prestação de contas da Administração.

Todos os mandamentos constitucionais que estabelecem os complexos e sofisticados sistemas de controle, fiscalização, responsabilização e representatividade [...] asseguram, viabilizam, equacionam, reiteram, reforçam e garantem o princípio republicano, realçando sua função primacial no sistema jurídico. Assim, funcionam eles como alicerces de toda a estrutura constitucional, pedras de toque ou chaves de abóboda do sistema (ATALIBA, 1985, p. 10).

O princípio republicano, hoje, demarca a responsabilidade do governante para com a coisa comum (res publica) e sua responsabilidade como gestor do interesse público. 
Por outro lado, o princípio do Estado Democrático de Direito veio delimitar outro campo referente à atividade do Estado. José Afonso da Silva (2000, p. 123-124) explica que a configuração do "Estado Democrático de Direito" não significa apenas unir formalmente os conceitos de Estado Democrático e Estado de Direito. Consiste, na verdade, na criação de um conceito novo, que leva em conta os conceitos dos elementos componentes. Esclarece o autor,

[...] a democracia que o Estado Democrático de Direito realiza há de ser um processo de convivência social numa sociedade livre, justa e solidária, em que o poder emana do povo, e deve ser exercido em proveito do povo, diretamente ou por representantes eleitos; participativa, porque envolve a participação crescente do povo no processo decisório e na formação dos atos de governo; pluralista, porque respeita a pluralidade de idéias, culturas e etnias e pressupõe assim o diálogo entre opiniões e pensamentos divergentes e a possibilidade de convivência de formas de organização e interesses diferentes da sociedade; há de ser um processo de liberação da pessoa humana das formas de opressão que não depende apenas do reconhecimento formal de certos direitos individuais, políticos e sociais, mas especialmente da vigência de condições econômicas suscetíveis de favorecer o seu pleno exercício.

Eurídio Bem-Hur Ferreira (1993) apresenta conclusões importantes sobre o princípio: na conjugação do Estado de Direito com democracia, o princípio revela componentes novos, principalmente no alargamento da compreensão da democracia, em que o termo democrático qualifica o Estado e não somente do direito e faz com que todos os aspectos, econômico, político, social do país, tenham de se organizar sob a égide da democracia.

Alguns autores consideram que o princípio republicano perdeu sua importância a partir do alargamento do conceito de democracia. Não concordamos com isto, pois o princípio do Estado Democrático de Direito, mesmo com um conteúdo bastante aberto, conhece limitações decorrentes do número de componentes do povo. Numa sociedade de massas, temos o governo de massas. A democracia é e continuará sendo, por muito tempo, representativa:

Quando o rei perdeu o poder para a nação, ela não conseguiu organizarse para exercê-lo senão através de um conjunto de seus membros, ou seja, 
a nação é muito grande para tomar decisões. Por outro lado, os assuntos de Estado são muito complexos e exigem agilidade no encaminhamento. Assim, a representação livre, com a independência do representante é conseqüência necessária para o exercício do poder (SOARES, 1997, p. 34).

Portanto, quando tratamos dos representantes do povo, do seu papel de gestores, encontramos seus limites no princípio republicano. Devem governar respeitando as manifestações e os anseios do povo (conforme o Estado Democrático de Direito). Anseios que não são unívocos, mas difusos, devendo ser condensados pelo representante. Nesse ambiente ele tem outros compromissos; resta, ainda, a responsabilidade com os bens públicos e com a gestão do interesse do povo. Enquanto o Estado Democrático de Direito impõe a vontade popular como determinante para a vida do Estado, o princípio republicano permanece na vida do Estado em razão da responsabilidade do representante do povo para com os bens e interesses públicos.

Assim, portanto, a exigência de publicidade está atrelada tanto ao Estado Democrático de Direito como ao princípio republicano. São duas faces da mesma moeda. De um lado, a publicidade proporciona a participação do povo nas decisões do Estado; de outro, possibilita o controle sobre bens e interesses do Estado (enquanto pessoa jurídica) por diversos órgãos de controle, fazendo com que, pela simples publicidade, evitemos mazelas no gerenciamento de bens e interesses públicos.

B) Princípios constitucionais gerais.- Quanto aos "princípios constitucionais gerais”, seguindo as explicações de Luís Roberto Barroso (1996), pelas quais eles são limitativos do poder do Estado e resguardam situações individuais (a grande maioria, encontra-se no capítulo dedicado aos direitos e deveres individuais), podemos extrair, então, os seguintes da Constituição (no que toca à publicidade): do "direito a informação" (art. 5믈 XXXIII, pelo qual todos têm direito a receber dos órgãos públicos informações de seu interesse particular, ou de interesse coletivo ou geral, que serão prestadas no prazo da lei, sob pena de responsabilidade, ressalvadas aquelas cujo sigilo seja imprescindível à segurança da sociedade e do Estado - é importante ressaltar que tal direito não se restringe à informação somente de interesse do indivíduo, mas também de interesse coletivo ou geral); e da "publicidade dos atos processuais" (art. 5a , LX, pelo qual a lei só poderá restringir a publicidade dos atos processuais quando a defesa da intimidade ou o interesse social o exigirem - embora tal princípio seja dirigido ao processo, aparentando, então, um princípio 
especial, entendemos tratar-se de um princípio geral, por ser limitativo do poder do Estado na proteção de direito de cidadania).

C) Princípios constitucionais especiais.- Nos "princípios constitucionais especiais", que são os que presidem um específico conjunto de normas afeto a determinado tema, capítulo ou título da Constituição, podemos incluir, retirando das linhas de Luís Roberto Barroso (1996, p. 148-149), os princípios: "da publicidade" (art. 37, caput - afeto à função administrativa) e da "publicidade e motivação das decisões judiciais e administrativas" (art. 93, IX e X - afetos ao Poder Judiciário e às funções jurisdicional e administrativa).

D) Regras constitucionais.- Por fim, quanto às "regras constitucionais", a exigência de publicidade como norma constitucional pode ser encontrada no art. 5ㅇ, XXXIV, letra b, que autoriza o "direito de obtenção de certidões em repartições públicas”, pelo qual é a todos assegurada a obtenção de certidão em repartições públicas, para defesa de direitos e esclarecimento de situações de interesse pessoal. Também é regra constitucional o dever imposto ao presidente da República de sancionar, promulgar e fazer "publicar as leis" (art. 84, IV). Ainda podemos incluir entre as regras constitucionais o art. $8^{\circ}$ da lei complementar $n^{\circ}$ 95/98, que dispõe sobre a elaboração, a redação, a alteração e a consolidação das leis: a vigência da lei será indicada de forma expressa e de modo a contemplar "prazo razoável para que dela se tenha amplo conhecimento", reservada a cláusula "entra em vigor na data de sua publicação" para as leis de pequena repercussão. Esta lei, podemos afirmar com base em Canotilho (1993, p. 69) 13 $^{13}$ tem conteúdo material de Constituição. Portanto, a lei que disciplina a formação das leis é, sob este ponto de vista, essencialmente constitucional.

\footnotetext{
13 'Não havendo uma 'reserva de constituição' as normas constitucionais podem estender-se a qualquer matéria. Não existe, porém, identidade entre constituição formal e constituição material: a matéria constitucional pode não ser disciplinada por normas formalmente constitucionais. Certas leis, no todo ou em parte, consideram-se materialmente constitucionais, sem serem formalmente constitucionais".
} 
O § 1으, do art. 37 da Constituição também contém uma regra constitucional. Ele possibilita a "publicidade dos atos, programas, obras, serviços e campanhas dos órgãos públicos os quais deverão ter caráter educativo, informativo ou de orientação social”. Conquanto o estudo deste dispositivo esteja reservado para a parte final deste trabalho, já é possível assegurar que ele determina comportamento específico, não é dotado de alto grau de abstração e exige ação determinada, ou seja, a divulgação de atos, programas, obras, serviços e campanhas dos órgãos públicos deverá perseguir uma dentre três finalidades possíveis: educar, informar e/ou propor orientações sociais.

Tanto o objeto da publicidade como os objetivos propostos não possuem alto grau de abstração, pelo contrário, são verbetes com conteúdo específico e com significado aferível por interpretação literal. O $\S 1^{\circ}$, do art. 37 da Constituição é, portanto, regra jurídica com grau de abstração reduzido e aplicação direta ${ }^{14}$ e tem "observância imediata, não necessitando para sua aplicação de qualquer regulamentação” (GASPARINI, 2001, p. 129). Tem conteúdo semântico suficiente para incidir diretamente sobre a realidade social. Esta afirmação também é encontrada na jurisprudência ${ }^{15}$.

O $\S 1^{\circ}$ do art. 37 da Constituição também é exemplo de regra jurídica bastante carregada de conteúdo axiológico. Ao indicar a publicidade como "meio" de divulgação de atos, programas, obras, serviços e campanhas e ao estabelecer certos objetivos a serem atingidos (educação, informação ou

\footnotetext{
${ }^{14}$ A regra jurídica inscrita no $\S 11^{a}$, do art. 37 da Constituição é norma jurídica de eficácia plena, nos termos da classificação da aplicabilidade das normas constitucionais proposta por José Afonso da Silva: "são de eficácia plena as normas constitucionais que: a) contenham vedações ou proibições; $b$ ) confiram isenções, imunidades e prerrogativas; c) não designem órgãos ou autoridades especiais, a que incumbam especificamente sua execução; d) não indiquem processos especiais de sua execução; e) não exijam a elaboração de novas normas legislativas que lhes completem o alcance e o sentido, ou lhes fixem o conteúdo, porque já se apresentem suficientemente explícitas na definição dos interesses nelas regulados”. Em seguida, o autor completa: estabelecem conduta jurídica positiva ou negativa com comando certo e definido, incrustando-se, predominantemente, entre as regras organizativas e limitativas dos poderes estatais, e podem conceituar-se como aquelas que, desde a entrada em vigor da constituição, produzem, ou têm possibilidade de produzir, todos os efeitos essenciais, relativamente aos interesses, comportamentos e situações, que o legislador constituinte, direta e normativamente, quis regular

15 "AÇÃO POPULAR - Propaganda e publicidade oficial de município - Artigo 37, § 1a , da Constituição da República - Aplicação - Norma de eficácia plena - Desnecessidade de regulamentação - Recurso não provido" (7ํㅡ Câm. Civ., TJ/SP, in JTJ/SP, São Paulo, LEX, v. 166, mar. 1995, p. 9.)
} 
orientação social), essa regra transmite valores protegidos pela sociedade, os quais devem ser protegidos via Judiciário, quando não observados. A publicidade, no caso, enquanto instrumento de condução dos interesses do Estado, é meio para a persecussão de certos objetivos de governo - objetivos do povo, também, portanto - quais sejam, a educação, a informação ou a orientação social, todos surgidos das decisões de governo que afetam diretamente o povo.

Por outro lado, Eros Roberto Grau (1997), citando Pietro Barcellona, explica que é impossível imaginarmos, de antemão, todas as circunstâncias possíveis de aplicação de uma regra, por isso é que elas são enunciadas em linguagem de textura aberta, configurando, mercê da abstração e generalidade que as caracteriza, um esquema formal potencialmente idôneo a compreender um número indefinido de casos, sob a única condição de que tais casos sejam redutíveis a tal esquema. Não podemos esquecer, então, que as normas são, por definição, genéricas e abstratas. Princípios e regras seguem essa linha, sendo possível afirmar, no entanto, que aqueles possuem grau de abstração muito elevado e pouca densidade semântica, ao passo que estas têm menor grau de abstração e maior densidade semântica. Especialmente quanto à regra do $\S 1^{\circ}$, do art. 37 , em questão, a situação não é diferente, ela tem textura aberta para incidir sobre um número indefinido de pessoas e abranger inúmeras circunstâncias reais, ela incide imediatamente sobre o fato concreto. Somente podemos aceitar dois tipos de atos intermediários entre tal dispositivo e sua realização no mundo dos fatos, o ato administrativo ou a decisão judicial (quando da correção de ato administrativo irregular).

É importante ressaltar, em conclusão, que a publicidade prevista no $\S 1$ o, do art. 37 da Constituição, é regra constitucional e sofre interferência, conforme propõe Canotilho (1993), dos princípios especiais (do princípio da publicidade, por exemplo, previsto no art. 37, caput), os quais sofrem influência dos princípios gerais (do direito à informação, por exemplo, previsto no art. $5^{\circ}$, XXXIII), sendo todos eles influenciados pelos princípios estruturantes, no caso, os princípios do Estado Democrático de Direito e o republicano, com todas as suas conseqüências. 


\section{OS LIMITES DA INTERPRETAÇÃO CONSTITUCIONAL E PROPAGANDA DOS ÓRGÃOS PÚBLICOS}

Conforme já afirmado, o princípio deve ser vetor para o intérprete. Para que isto ocorra, o aplicador do direito deve respeitar o texto normativo a interpretar e, mais do que isto, as opções políticas encontradas no texto da Constituição. Contudo, considerando o alto grau de abstração dos princípios jurídicos e a existência de inúmeros deles, bem como o confronto político permanentemente vivido numa sociedade, são indispensáveis, além da referência a um sistema jurídico, "barreiras de contenção" àqueles aplicadores do direito que podem seguir caminhos diferentes do caminho proposto na Constituição.

Nossa intenção, neste tópico, é demarcar algumas posições relevantes para o objeto de nosso estudo. Numa sociedade onde o processo

Democrático (SILVA, 2000) ${ }^{16}$ ainda depende de alguns passos importantes para sua consolidação, o desrespeito ao interesse público deve ser combatido veementemente, para servir de parâmetro de democratização da sociedade. $\mathrm{O}$ direito, aqui, tem um papel educativo e transformador. $\mathrm{O}$ estudo da interpretação da Constituição, neste caso, tem por objetivo "demarcar limites que o intérprete da regra constitucional de propaganda dos órgãos públicos deve respeitar".

Estudando o capítulo sobre interpretação, do livro Teoria Pura do Direito de Hans Kelsen (1979), encontramos dois extremos. Segundo o autor, existem duas espécies de interpretação que devem ser distinguidas claramente uma da outra: a interpretação do Direito pelo órgão que o aplica, e a interpretação do Direito que não é realizada por um órgão jurídico mas por uma pessoa privada e, especialmente, pela Ciência Jurídica. Aquela, é ato de conhecimento e de vontade "em que o órgão aplicador do Direito efectua uma escolha entre as possibilidades reveladas" através de interpretação cognoscitiva. Esta, é puro ato de conhecimento do estudioso do Direito na determinação do sentido das normas jurídicas (sentido já embutido na norma). A segunda

\footnotetext{
${ }^{16}$ José Afonso da Silva explica que democracia "é conceito histórico. Não sendo por si um valor-fim, mas meio e instrumento de realização de valores essenciais de convívio humano, que se traduzem basicamente nos direitos fundamentais do homem, compreende-se que a historicidade destes a envolva na mesma medida, enriquecendo-lhe o conteúdo a cada etapa do evolver social, mantido sempre o princípio básico de que ela revela um regime político em que o poder repousa na vontade do povo. Sob esse aspecto, a democracia não é um mero conceito político abstrato e estático, mas é um processo de afirmação do povo e de garantia dos direitos fundamentais que o povo vai conquistando no correr da história”.
} 
interpretação é resultado da Ciência Jurídica, a primeira é questão "jurídico-política" de política do Direito. Kelsen separa a Ciência do Direito do ambiente real de aplicação da lei. A aplicação da norma, da lei, é, portanto, uma questão política e não da Ciência do Direito.

A interpretação das normas referentes à propaganda do governo tem seguido, em muitos casos, essa linha política de aplicação, o que não pode ser aceito. Por outro lado, a Ciência do Direito também tem procurado a superação da teoria kelseniana, nesse capítulo da interpretação. A acomodação do princípio como norma jurídica, o reconhecimento de conteúdo axiológico na norma, a recriação de sistemas jurídicos, a busca de novos métodos de interpretação, tudo isto evita aqueles dois extremos apresentados por Kelsen, levando à possibilidade de unificação daquelas duas espécies de interpretação (para que ela não seja puramente política ou puramente acadêmica).

Encontramos em Konrad Hesse (1983) a idéia de concretização do direito: A concretização é a determinação do conteúdo da norma feita a partir da inclusão de dados da realidade social por um intérprete que carrega sua pré-compreensão quando da interpretação; a concretização em Hesse apresenta-se como um processo pelo qual norma jurídica (a Constituição) e problema (dados da realidade social) são adequados um ao outro, mas sempre seguindo o que está determinado na norma, ou seja, a norma serve de orientação (de parâmetro) que o intérprete deve ter em vista, sem fugir de seus ditames. Mais adiante o autor trata dos limites da interpretação (HESSE, 1983): os limites da interpretação surgem da necessidade de estabelecer limites a essa atividade, sob pena de chegarmos a soluções aleatórias. Os limites da interpretação encontramos onde: (1 $\left.{ }^{a}\right)$ não existe uma determinação constitucional vinculante, onde, então, não é possível uma compreensão lógica do texto; $\left(2^{\underline{a}}\right)$ a solução encontrada contraria o texto da norma. No primeiro caso temos as limitações referentes ao texto normativo, no segundo temos as limitações impostas quando do enfrentamento do problema: o problema não pode ter solução que vá além das possibilidades na norma; da norma não se pode retirar solução que o próprio texto não apresente (quando utilizada a interpretação lógica ou a sistemática, por exemplo). O texto da norma acaba como limite intransponível na interpretação constitucional, mesmo, e principalmente, quando da confrontação com o problema. 
Para Canotilho, é legítima a adequação dialética entre o "programa normativo" (enunciados lingüísticos da Constituição) e a realidade social. Mas ele nega veementemente as

[...] tentativas de legitimação de uma interpretação constitucional criadora que, com base na força normativa dos factos, pretenda 'constitucionalizar' uma alteração constitucional em inequívoca contradição com a constitutio scripta. [...] Esta leitura da constituição de baixo para cima, justificadora de uma nova compreensão da constituição a partir das leis infraconstitucionais, pode conduzir à derrocada interna da constituição por obra do legislador e de outros órgãos concretizadores, e à formação de uma constituição legal paralela (1993, p. 232).

Entre os autores nacionais, essa postura é bem demarcada por Anna Candida da Cunha Ferraz (1986, p. 243-244), para quem as mudanças nãoformais na Constituição ocorrem dentro dos limites constitucionais e não alteram a letra nem o espírito da Constituição, mas adaptam-na à realidade, atribuindo-lhe novo sentido, renovando significado e ampliando-lhe ou restringindo-lhe o alcance. Contudo, tais mudanças devem respeitar limites ou serão inconstitucionais: "os processos de mutação inconstitucional desbordam os 'limites de forma' ou 'fundo' fixados pelo constituinte e de observância obrigatória pelos órgãos de aplicação constitucional”. Celso Ribeiro Bastos (1999, p. 110) faz uma demarcação objetiva: a letra da lei constitui sempre o ponto de referência obrigatório para a interpretação de qualquer norma, e isto num sentido dúplice, pois a letra da lei é o ponto de partida de sua interpretação e, mais adiante, será o limite da mesma (FERRAZ JUNIOR, 1973) ${ }^{17}$.

\footnotetext{
${ }^{17}$ Tercio Sampaio Ferraz Junior demonstra existir limites em um sistema jurídico. Examinando a língua como um sistema aberto ele explica: "se, numa frase de cinco palavras, eu tiver quatro inglesas e uma portuguesa, eu quebro a estrutura do português. Então há um certo limite para a abertura de um sistema”. Podemos afirmar, daí, que o sistema jurídico também tem limite de saturação, para assimilar qualquer elemento externo, desrespeitar os limites de um sistema implica em seu desmantelamento. Explicando o modelo de sistema jurídico circular, dinâmico e aberto, o autor assevera: "o sistema circular constitui limite entre limites. Isto é, o sistema circular parte da idéia, também, de que o sistema, como tal, estabelece um limite e que limite tem, digamos assim, um aspecto interno e um aspecto externo. $\mathrm{O}$ aspecto externo é um outro sistema. Isto é, todo o sistema está limitado com outros sistemas. Mas ao estar limitado com outros sistemas, ele está aberto para os outros sistemas; quer dizer, ele está constantemente em comunicação com outros sistemas. Assim, no sistema circular, apesar da idéia de o círculo ser fechado, há um momento em que o círculo se inicia, por assim dizer; isto é um momento em que a informação entra. E há um momento em que o círculo se fecha, isto é, um momento em que a informação sai, volta para o mundo circundante do sistema. Então, como vêem, há um canal de entrada e há um canal de saída” .
} 
A lei é, então, referência obrigatória para o intérprete. Nesta condição ela é fundamental para a democracia, como instrumento de transformação. André Franco Montoro (1997) explica: o direito pode - e deve - ser encarado sob duas perspectivas diferentes: como elemento de conservação das estruturas sociais, ou como instrumento de promoção das transformações institucionais da sociedade. É natural que, em países plenamente desenvolvidos, estabilizados e organizados, prevaleça a função conservadora do direito. Mas principalmente nos países em desenvolvimento e transformações profundas, o erro dessa posição é patente. Reduzir o direito a uma força conservadora é perpetuar o subdesenvolvimento e o atraso. É tão grande sua capacidade de conservar as instituições, como a de tornar-se o principal agente de mudança social. Essa função transformadora do direito ganha importância maior nos períodos de crise e nos momentos em que o desenvolvimento econômico e social do país torna-se imperativo histórico.

\section{CONCLUSÃO}

De tudo o que foi visto até aqui, podemos dizer que a Constituição é limite intransponível ao aplicador do direito (DIMOULIS, 1999) ${ }^{18}$. Não é possível aceitar uma interpretação dos dispositivos constitucionais que não corresponda ao modelo de Estado ali estabelecido. Isto tem acontecido com a "propaganda do governo", pois ela é veiculada, muitas vezes, sem cumprir o mister enunciado no art. $37, \S 1^{\underline{a}}$ (veicular atos, programas, obras, serviços e campanhas dos órgãos públicos, bem como ter caráter educativo, informativo ou de orientação social). Os órgãos de governo do Estado, inclusive o Judiciário, na aplicação deste dispositivo constitucional, têm adotado postura inadequada à prevista na Constituição, o que é um caminho

\footnotetext{
${ }^{18}$ Merece registro o estudo de Dimitri Dimoulis sobre a inserção de elementos subjetivos na interpretação da norma jurídica. Ele desenvolve seu estudo demonstrando a incoerência dessa inserção e indicando a viabilidade de uma interpretação calcada estritamente no positivismo. Apesar de descordarmos de tal postura, vale a referência à lei como limite do intérprete e o perigo de interferências subjetivas no resultado da interpretação da Constituição.
} 
para a expansão do poder daqueles que exercem os cargos públicos (isto fica evidente especialmente em períodos pré-eleitorais, quando a "máquina administrativa" é usada para informar a sociedade sobre a administração pública - mas, por incrível que possa parecer, nestas "informações à sociedade" encontramos somente boas referências da administração).

A interpretação da Constituição tem como referência normas constitucionais (princípios e regras) e desenvolve-se sobre um sistema jurídico dinâmico e aberto, mas o texto da Constituição continua como limite intransponível para o intérprete. Isto também vale para a "propaganda dos órgãos públicos", instrumento muito eficiente para a comunicação entre governo e sociedade, que pode ser voltada para o interesse pessoal. A ampla possibilidade de manipulação da propaganda para promover interesses estranhos ao interesse público exige do aplicador da Constituição um cuidado especial na interpretação do $\S 11^{\circ}$, do art. 37.

\section{REFERÊNCIAS}

ATALIBA, G. República e Constituição. São Paulo: Revista dos Tribunais, 1985.

BARROSO, L. R. Fundamentos teóricos e filosóficos do novo direito constitucional brasileiro (Pós-modernidade, teoria crítica e pós-positivismo). Revista Forense, Rio de Janeiro, v. 358, p. 91- 114, 2001.

. Interpretação e aplicação da constituição. São Paulo: Saraiva, 1996.

BASTOS, Celso Ribeiro. Curso de direito constitucional. 18. ed. São Paulo: Saraiva, 1997.

. Hermenêutica e interpretação constitucional. 2. ed. São Paulo: Instituto Brasileiro de Direito Constitucional, 1999.

BOBBIO, N. O positivismo jurídico: lições de filosofia do direito, compiladas por Nello Morra. (Trad.) Márcio Pugliesi e Edson Bini. São Paulo: Ícone, 1995.

Teoria do ordenamento jurídico. 10. ed. Brasília: UNB, 1997.

BONAVIDES, P. Curso de direito constitucional.12. ed. São Paulo: Malheiros, 2002.

CANOTILHO, J. J. G. Direito constitucional. 6. ed. Coimbra: Almedina, 1993.

CARRAZZA, R. A. Curso de direito constitucional tributário. 2. ed. São Paulo: Revista dos Tribunais, 1991.

DALLARI, D. de A. Elementos de teoria geral do estado. 16. ed. São Paulo: Saraiva, 1991.

DANTAS, Ivo. Dos princípios constitucionais fundamentais. Rio de Janeiro: Lumen Juris, 1995. 
DIMOULIS, D. Moralismo, positivismo e pragmatismo na interpretação do Direito Consitucional. Revista dos Tribunais, São Paulo, v. 88, n. 769, p. 1127, nov./ 1999.

DINIZ, Maria Helena. As lacunas no direito. 3.ed. São Paulo: Saraiva, 1995. FERRAZ, Anna Candida da Cunha. Processos informais de mudança da constituição. São Paulo: Max Limonad, 1986.

FERRAZ JUNIOR, T. S. Sistema jurídico e teoria geral dos sistemas. In: ASSOCIAÇÃO DOS ADVOGADOS DE SÃO PAULO. Curso de extensão universitária. Apostila. São Paulo, 1973.

FERREIRA, E. B. H. Estado democrático de direito e a participação popular na Constituição Federal de 1988. 1993. Dissertação (Mestrado) - Pontifícia Universidade Católica de São Paulo. São Paulo.

FERREIRA, P. Princípios gerais do direito constitucional moderno. 6. ed. v.1. São Paulo: Saraiva, 1983.

FIGUEIREDO, L. V. Curso de direito administrativo. 5. ed. São Paulo: Malheiros, 2001.

GASPARINI, D. Direito administrativo. 6. ed. São Paulo: Saraiva, 2001. GRAU, E. R. A ordem econômica na constituição de 1988. 3. ed. São Paulo: Malheiros, 1997.

HESSE, K. Escritos de derecho constitucional. Madrid: Centro de Estudios Constitucionales, 1983.

JARDIM, T. Organização do estado brasileiro. Revista de Direito Público, São Paulo, v. 25, n. 100, p. 45-61, out./dez./1991.

KELSEN, H. Teoria pura do direito. 5. ed. Coimbra: Armênio Amado, 1979 .

MEDAUAR, O. Direito administrativo moderno. 2. ed. São Paulo: Revista dos Tribunais, 1998.

MELlO, C. A. B. de. Curso de direito administrativo. 13. ed. São Paulo: Malheiros, 2001.

MONTORO, A. F. Introdução à ciência do direito. 24. ed. São Paulo: Revista dos Tribunais, 1997.

REALE, M. Lições preliminares de direto. 8. ed. São Paulo: Saraiva, 1981. . Teoria do direito e do estado. 2. ed. São Paulo: Martins, 1960. 
ROCHA, C. L. A. A Constituição segundo a lei eleitoral ou a lei eleitoral segundo a Constituição. Paraná Eleitoral, Curitiba, n.30, out./dez./1998.

. Princípios constitucionais da administração pública. Belo Horizonte: Del Rey, 1994.

SILVA, J. A. da. Aplicabilidade das normas constitucionais. 2. ed. São Paulo: Revista dos Tribunais, 1982.

. Curso de direito constitucional Positivo. 17. ed. São Paulo, Malheiros, 2000.

SOARES, M. A. S. O princípio da representação popular e o controle jurídico sobre os atos do eleito. Cadernos de Direito Constitucional e Ciência Política, São Paulo, n. 21, p. 338-354, out./dez./1997.

SOUZA, B. de. A publicidade dos contratos da administração pública. Interesse Público, Sapucaia do Sul, v. 1, n. 1, p. 47, jan./mar./1999.

SUNDFELD, C. A. Fundamentos de direito público. 2. ed. São Paulo: Malheiros, 1993.

TAVARES, A. R. Curso de direito constitucional. São Paulo: Saraiva, 2002. 
